\title{
BMJ Open Challenges to discussing palliative care with people experiencing homelessness: a qualitative study
}

\author{
Briony F Hudson, ${ }^{1,2}$ Caroline Shulman, ${ }^{1,2,3}$ Joseph Low, ${ }^{2}$ Nigel Hewett, ${ }^{1}$ \\ Julian Daley, ${ }^{1}$ Sarah Davis, ${ }^{2}$ Nimah Brophy, ${ }^{4}$ Diana Howard, ${ }^{5}$ Bella Vivat, ${ }^{2}$ \\ Peter Kennedy, ${ }^{1,4}$ Patrick Stone ${ }^{2}$
}

\begin{abstract}
To cite: Hudson BF, Shulman C, Low J, et al. Challenges to discussing palliative care with people experiencing homelessness: a qualitative study. BMJ Open 2017;7:e017502. doi:10.1136/ bmjopen-2017-017502

- Prepublication history and additional material for this paper are available online. To view these files, please visit the journal online (http://dx.doi. org/10.1136/bmjopen-2017017502).
\end{abstract}

Received 27 April 2017 Revised 6 September 2017 Accepted 6 October 2017

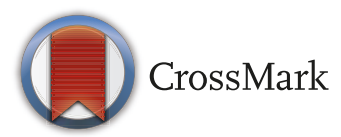

${ }^{1}$ Pathway, London, UK ${ }^{2}$ Marie Curie Palliative Care Research Department, Division of Psychiatry, UCL, London, UK ${ }^{3}$ Kings Health Partners, Kings College Hospital, London, UK

${ }^{4}$ St Mungos, London, UK

${ }^{5}$ Coordinate My Care, The Royal Marsden NHS Foundation Trust, London, UK

Correspondence to Professor Patrick Stone; p.stone@ucl.ac.uk

\section{ABSTRACT}

Objectives To explore the views and experiences of people who are homeless and those supporting them regarding conversations and approaches to palliative care Setting Data were collected between October 2015 and October 2016 in homeless hostels and day centres and with staff from primary and secondary healthcare providers and social care services from three London boroughs.

Participants People experiencing homelessness $(n=28)$, formerly homeless people $(n=10)$, health and social care providers $(n=48)$, hostel staff $(n=30)$ and outreach staff $(n=10)$.

Methods In this qualitative descriptive study, participants were recruited to interviews and focus groups across three London boroughs. Views and experiences of end-of-life care were explored with people with personal experience of homelessness, health and social care professionals and hostel and outreach staff. Saturation was reached when no new themes emerged from discussions.

Results 28 focus groups and 10 individual interviews were conducted. Participants highlighted that conversations exploring future care preferences and palliative care with people experiencing homelessness are rare. Themes identified as challenges to such conversations included attitudes to death; the recovery focused nature of services for people experiencing homelessness; uncertainty regarding prognosis and place of care; and fear of negative impact.

Conclusions This research highlights the need for a different approach to supporting people who are homeless and are experiencing advanced ill health, one that incorporates uncertainty and promotes well-being, dignity and choice. We propose parallel planning and mapping as a way of working with uncertainty. We acknowledge that these approaches will not always be straightforward, nor will they be suitable for everyone, yet moving the focus of conversations about the future away from death and dying, towards the present and the future may facilitate conversations and enable the wishes of people who are homeless to be known and explored.

\section{INTRODUCTION}

Homelessness is a growing problem in the UK and internationally. The Public Health England definition of 'homelessness'

\section{Strengths and limitations of the study}

- This is the largest qualitative UK study to date exploring the views and experiences of people who are homeless and those supporting them regarding conversations and approaches to palliative care.

- The views of rough sleepers who are not using day centres are not represented in this research.

- People who were intoxicated were unable to provide informed consent, and so did not participate. Thus, people experiencing homeless who also have severe substance misuse issues are likely to be underrepresented.

- Given the exploratory nature of the research, the characteristics of participants could not be predetermined.

- People experiencing homelessness were initially approached regarding participation in the study by hostel and day centre staff. It is therefore unknown who declined to participate, how or whether they differ from those that took part and the extent to which gatekeeping impacted recruitment.

includes people without shelter of any kind (rough sleeping), those sleeping in temporary accommodation (such as hostels) and those living in insecure or inadequate housing. ${ }^{1}$ Rough sleeping is rising in England with a total increase of $133 \%$ since $2010 .^{2}$ Homelessness is associated with ill health ${ }^{3}$ often including drug and/or alcohol dependence and mental health problems in association with physical health issues. ${ }^{45}$ People experiencing homelessness have high rates of premature mortality from suicide and accidental injuries and an increased prevalence of cancer, ${ }^{6}$ infectious and non-communicable diseases and evidence of accelerated ageing. ${ }^{7}$ The stark inequities between the housed and homeless populations are perhaps best highlighted by the average age of death for people experiencing homelessness, which is approximately 30 years younger than that of the housed population. ${ }^{8}$ 
People experiencing homelessness often underuse primary care services while their use of emergency healthcare services is higher than the general population. ${ }^{9}$ Challenges to primary healthcare access include mistrust of healthcare providers, ${ }^{1011}$ perceived stigma and discrimination, ${ }^{12}$ competing priorities ${ }^{10}$ difficulties registering with general practitioners (GPs) ${ }^{13}$ and keeping appointments. ${ }^{12}$

People experiencing homelessness rarely have access to palliative care support or services. ${ }^{14-16}$ Recognition of the inequalities in access to palliative care has led to the development of research exploring how best to support people who are homeless with advanced ill health. ${ }^{16-21}$ Palliative care, as we refer to in this manuscript, seeks to improve the quality of life of people with life-limiting or life-threatening illnesses, addressing pain and symptom management alongside social, psychological and spiritual support. ${ }^{22} 23$

Previous research exploring end-of-life or palliative care issues with this group has used focus groups ${ }^{1924}$ or individual interviews. ${ }^{26} 27$ Other studies have interviewed professionals supporting homeless people around these issues. ${ }^{11}{ }^{28-32}$ The importance of continuity of care, integration and collaboration between services supporting homeless people has been highlighted. ${ }^{33} 34$ Advance directive forms have been designed specifically for marginalised population, ${ }^{35}$ and research suggests that people who are homeless can and will complete them, and that guidance around this can facilitate completion. ${ }^{36}{ }^{37}$ In a single-arm intervention study, $74 \%$ of participants experiencing homelessness reported that completing a counsellor-led advance directive made them feel at peace while $16.3 \%$ reported participation left them feeling anxious. ${ }^{36}$ A recent systematic review has indicated that there is a need for more research to explore approaches to palliative care, advance care planning and end-of-life care for people who are homeless. ${ }^{38}$

Our previous research highlighted a lack of meaningful conversation around the future wishes and care preferences of people experiencing homelessness in the $\mathrm{UK}^{16}$ leaving the preferences of many people with advanced ill health unknown. In this paper, we explore in more detail some of the reasons why these conversations are not taking place from the perspectives of both people experiencing homelessness: formerly homeless people and those supporting them.

\section{Aims}

To explore the views and experiences of people experiencing homelessness, formerly homeless people and those supporting them regarding conversations and approaches to palliative care.

\section{METHODS}

\section{Participants and recruitment}

Participants in this qualitative descriptive study were recruited from three London boroughs, selected for their
Box Eligibility criteria for participants

Health and social care providers, hostel and outreach staff

- Direct professional contact with people who are homeless

Experience of working within services for people who are homeless within one or more of included boroughs

People with previous lived experience of homelessness

- More than 6 months lived experience of homelessness

- Securely housed for more than 6 months*

Able and willing to articulate experiences and views

People currently experiencing homelessness

- Currently homeless or living in a hostel, for longer than 6 months

- 'Single homeless people' - that is, without dependants in their care ${ }^{65}$ Entitled to UK housing benefit, which pays for hostel accommodation who were. Considered appropriate to be approached by key worker (ie, psychologically robust)

- Not under influence of drugs or alcohol during participation (assessed by researcher at start of data collection session)

Fluent in English

*People with lived experience of homelessness and hostel staff advised us to use 6 months as the marker for housing status.

high numbers of both people experiencing homeless and homelessness services. ${ }^{39}$ Frontline homelessness staff and health and social care professionals were recruited through mapping homelessness services within these boroughs. ${ }^{40}$ Formerly homeless people were recruited through homelessness charities: Pathway, ${ }^{41}$ Groundswell ${ }^{42}$ and St Mungo's. ${ }^{43}$ People experiencing homelessness were identified and recruited by staff at homeless hostels and day centres, as advised in consultations with hostel staff and people with lived experience of homelessness. Given the exploratory nature of the research, the characteristics of participants could not be predetermined. CS had encountered some but not all of the hostel staff and healthcare professionals in her clinical work.

Eligibility criteria are outlined in box. People with current and previous experience of homelessness were provided with a $£ 10$ supermarket voucher for participation. Full details of recruitment and data collection are described elsewhere. ${ }^{16}$ Participants were offered the choice of taking part in a focus group or individual interview, as advised in consultations with people with lived experience of homelessness and hostel staff.

\section{Data collection}

Semistructured interviews and focus groups were conducted between October 2015 and October 2016 to explore the views and experiences of people experiencing homelessness, formerly homeless people, frontline homelessness staff, and health and social care professionals, regarding palliative care. Data were collected by CS (lead clinical researcher), BH (mixed methods researcher) and JD (person with lived experience of homelessness). The exploratory nature of the research was emphasised to participants before and during data collection. Data were 


\begin{abstract}
John is a 30 year old man. He has been a heavy drinker since his early 20s. He was rough sleeping,
squatting and sofa surfing for a number of years and is currently in a hostel. He has had frequent

attendances to hospital with alcohol related fits, vomiting blood and has been diagnosed with liver

cirrhosis. Three hospital attendances resulted in short admissions for detox. Following each

admission he started drinking again and missed follow up appointments with hospital and

community alcohol teams. The doctors have said that if he continues to drink, he is unlikely to live

for more than 6-12 months.
\end{abstract}

Figure 1 Vignette used during data collection.

collected until no new themes emerged and thematic saturation was achieved. ${ }^{44}$

Focus groups were based around a vignette (figure 1) and lasted approximately 3 hours for hostel, outreach staff and formerly homeless people and 1 hour for health and social care providers and people experiencing homelessness (see online supplementary file S1). They took place in locations that were convenient and known to participants. All participants completed demographic sheets. Data collection was audio recorded, transcribed verbatim, field notes were taken and summaries circulated to participants. No changes were requested. No repeat interviews were conducted.

\section{Ethical considerations and informed consent}

Written consent was obtained from formerly homeless people and staff. Following consultation with hostel staff and formerly homeless people, verbal consent witnessed by a key worker was deemed the most appropriate consenting method for people experiencing homelessness as disclosing literacy difficulties was felt to be potentially off putting for some.

\section{Analysis}

The analytic technique used in this research was thematic analysis, in line with guidance from Braun and Clarke. ${ }^{45}$ In this analysis, the data set was all data coded 'end-of-life conversations' in the data corpus. A full description of all themes from the data corpus is provided elsewhere. ${ }^{16}$ The data set was analysed by BH (using Nvivo) to explore the challenges of discussing palliative care and future healthcare needs and preferences with people experiencing homelessness from a critical realist standpoint. This epistemological position enabled both participants' individual meaning making and the wider social context to be considered. Additionally, a focus remained on what is commonly and materially defined as reality, planting the narratives in a socially constructed and accepted framework. ${ }^{46}$

Initial codes in the data set were identified through examination of summaries and field notes taken during data collection, and discussion between BH and CS. Datadriven, line-by-line coding was undertaken by $\mathrm{BH}$, and new codes were created as necessary in addition to those identified in field notes to reflect the data.
The codes were then analysed and grouped to create higher level candidate themes and subthemes to categorise the data. These were refined following discussion (BH and $\mathrm{CS}$ ) and returning to transcripts for verification. These candidate themes and subthemes were discussed with a wider group of healthcare professionals, researchers and formerly homeless people, who formed the research steering committee, for authentication.

\section{RESULTS}

\section{Participants}

Twenty-eight focus groups and 10 individual semistructured interviews were conducted with 127 participants (28 people experiencing homelessness, 10 formerly homeless people, 49 health and social care providers and 40 hostel and outreach staff). Participant characteristics are outlined in table 1 . Over a third $(11 / 28)$ of people experiencing homelessness had been homeless for over 5 years, 24/28 participants had slept on the streets (slept rough) and 20/28 reported currently mainly sleeping in hostels (table 2).

Challenges to conversations about palliative care, future health options and preferences identified in this research are categorised into four main themes (table 3).

\section{Theme 1: attitudes to death}

Both service users and staff found death difficult to discuss. Hostel and outreach workers experienced discomfort in raising topics related to the potential death of a service user in many situations, including conversations between staff.

There was a meeting [with other staff] and I said, listen, I think he's dying ....and it was like I'd taken a hand grenade out my pocket and threatened to remove the pin... people were taken aback. I was just reporting it...I thought it was urgent...then I began to feel foolish but he [homeless person] didn't discuss or raise it. And I think he must have known.

(Outreach worker)

The reluctance and avoidance of talking about death and dying expressed by staff was often mirrored by people experiencing homelessness who tended to focus on the present rather than future care needs. 
Table 1 Characteristics of health and social are providers, frontline homeless staff and formerly homeless people

Health and social care providers, hostel and outreach staff

\begin{tabular}{|c|c|c|c|c|}
\hline & $\begin{array}{l}\text { Total } \\
\mathrm{n}=99\end{array}$ & $\begin{array}{l}\text { Health and social } \\
\text { care providers } \\
n=49\end{array}$ & $\begin{array}{l}\text { Hostel/outreach } \\
\text { staff } \\
n=40\end{array}$ & $\begin{array}{l}\text { People with previous } \\
\text { lived experience of } \\
\text { homelessness } \\
n=10\end{array}$ \\
\hline \multicolumn{5}{|l|}{ Borough } \\
\hline$A$ & 18 & 9 & 8 & 1 \\
\hline B & 23 & 7 & 12 & 4 \\
\hline C & 39 & 27 & 12 & - \\
\hline Multiple & 14 & 6 & 8 & - \\
\hline Not reported & 5 & - & - & 5 \\
\hline \multicolumn{5}{|l|}{ Place of work } \\
\hline Outreach service & 14 & 12 & - & 2 \\
\hline Hospital & 15 & 14 & - & 1 \\
\hline GP surgery & 7 & 7 & - & - \\
\hline Hospice & 7 & 7 & - & - \\
\hline Hostel & 31 & 3 & 26 & 2 \\
\hline Care home & 7 & - & 7 & - \\
\hline Day centre & 5 & - & 5 & - \\
\hline Supported housing & 2 & - & 2 & - \\
\hline Council & 6 & 6 & - & - \\
\hline Not reported & 5 & - & - & 5 \\
\hline \multicolumn{5}{|l|}{ Job title } \\
\hline GP & 4 & 4 & - & - \\
\hline Nurse practitioner & 7 & 7 & - & - \\
\hline Nurse specialist & 11 & 11 & - & - \\
\hline Drug and alcohol worker & 2 & 2 & - & - \\
\hline Addiction psychiatrist & 2 & 2 & - & - \\
\hline Palliative care consultant & 2 & 2 & - & - \\
\hline $\begin{array}{l}\text { Social worker in homelessness or palliative } \\
\text { care }\end{array}$ & 8 & 8 & - & - \\
\hline Clinical psychologist & 2 & 2 & - & - \\
\hline Liver specialist & 1 & 1 & - & - \\
\hline Service manager & 1 & 1 & - & - \\
\hline Housing commissioner & 4 & 4 & - & - \\
\hline Housing worker & 5 & 3 & - & 2 \\
\hline Hostel worker & 17 & 1 & 16 & - \\
\hline Care navigator & 1 & - & - & 1 \\
\hline Outreach worker & 12 & - & 10 & 2 \\
\hline Complex needs hostel worker & 6 & - & 6 & - \\
\hline Hostel manager & 7 & - & 7 & - \\
\hline Day centre manager & 1 & - & 1 & - \\
\hline Not reported & 6 & 1 & - & 5 \\
\hline \multicolumn{5}{|l|}{ Years of experience working in homelessness } \\
\hline Less than 1 year & 4 & 2 & 2 & - \\
\hline $1-4$ years & 17 & 8 & 6 & 3 \\
\hline $5-10$ years & 27 & 16 & 9 & 2 \\
\hline
\end{tabular}


Table 1 Continued

Health and social care providers, hostel and outreach staff

\begin{tabular}{|c|c|c|c|c|}
\hline & $\begin{array}{l}\text { Total } \\
\mathrm{n}=99\end{array}$ & $\begin{array}{l}\text { Health and social } \\
\text { care providers } \\
\mathrm{n}=49\end{array}$ & $\begin{array}{l}\text { Hostel/outreach } \\
\text { staff } \\
n=40\end{array}$ & $\begin{array}{l}\text { People with previous } \\
\text { lived experience of } \\
\text { homelessness } \\
n=10\end{array}$ \\
\hline 11-15years & 23 & 17 & 6 & - \\
\hline 15 years + & 14 & 5 & 9 & - \\
\hline Not reported & 14 & 1 & 8 & 5 \\
\hline Yes & 30 & 8 & 11 & 10 \\
\hline No & 61 & 41 & 21 & - \\
\hline Not reported & 8 & - & 8 & - \\
\hline \multicolumn{5}{|l|}{ Gender } \\
\hline $1-4$ years & - & - & - & 6 \\
\hline 5-10years & - & - & - & 2 \\
\hline $11-15$ years & - & - & - & 1 \\
\hline Not reported & - & - & - & 1 \\
\hline
\end{tabular}

GP, general practitioner.

A lot of people are frightened to think about it. Most people won't talk about it, they won't entertain talking about it. They see it as so far away, you know? (Person experiencing homelessness)

Healthcare professionals described how the fatalistic approach to death, informed by previous negative life experiences and circumstances made palliative care a difficult subject to raise with some people who are homeless:

I...I've just found it [palliative care conversations] very difficult. Especially with the alcohol and liver disease. I have found it very difficult to get an acceptance that actually, if I carry on the way I'm going... or even if they accept it, they are very fatalistic about things. They say "look, my life is...I'm living in a room, injecting heroin. I'm not...this isn't really a great life, I don't really care if I live or I die”. So it's all very sort of fatalistic. And, you know...that's difficult to combat. But...I mean, they are difficult conversations at any time (Health care professional)

The inevitability of death was seen as a barrier to palliative care conversations by other services users:

Researcher: we've got someone who is really really sick, and we want to find out what would make his life, his last few months of life better...

Service user: that is so depressing man...What's the point... If he'll be dead in 6 months?
Other people experiencing homelessness expressed denial or disbelief that behaviours or an illness could lead to death.

I didn't even know he was ill to be honest... I knew he was a drinker, but I didn't know it was so serious...that he was going to peg it [to die]. (Person experiencing homelessness)

\section{Theme 2: recovery focus}

Many homelessness services focus on recovery, including helping people access and engage with addiction services and move towards independent living. While this ethos undoubtedly serves some well, some healthcare professionals questioned what 'recovery' means in the context of homelessness, and how useful this was as a goal for those with advanced ill health:

When I first came into this I, I initially thought that this is about recovery, it's not... realistically it can't be... and it isn't. Very few people recover. You have to learn to accept that, it's about giving people the best quality care, respect, choices and whatever and palliative... and it's a version of palliative care, isn't it? Really? (Healthcare professional)

This recovery focus does little to encourage dialogue around the fact that young people experiencing homelessness may not always be able to 'recover'. Hostel staff have very little experience around exploring options 
Table 2 Characteristics of participants who are currently experiencing homelessness

\begin{tabular}{lc}
\hline People experiencing homelessness & $\mathbf{n = 2 8}$ \\
\hline Gender & \\
Male & 26 \\
Female & 2
\end{tabular}

How long have you been homeless?

\begin{tabular}{|cc}
\hline Less than 1 year & 4 \\
\hline $1-4$ years & 9 \\
\hline $5-10$ years & 6 \\
\hline $10-15$ years & - \\
\hline 15years + & 5 \\
\hline Not reported & 4 \\
\hline Have you ever slept rough? & \\
\hline Yes & 24 \\
\hline No & 1 \\
\hline Not reported & 3 \\
\hline How would you describe your health overall? & \\
\hline Poor & 8 \\
\hline Fair & 12 \\
\hline Good & 4 \\
\hline Very good & 1 \\
\hline Not reported & 3 \\
\hline Do you use drugs? & \\
\hline Yes & 7 \\
\hline No & 16 \\
\hline Not reported & 5
\end{tabular}

Not reported

5

Do you use methadone/subutex (buprenorphine)?

$\begin{array}{lr}\text { Yes } & 3 \\ \text { No } & 20\end{array}$

Not reported

5

Do you drink alcohol?

\begin{tabular}{lr}
\hline Yes & 21 \\
\hline No & 2 \\
\hline Not reported & 5 \\
\hline $\begin{array}{l}\text { Have you been to A\&E* in the last year? } \\
\text { Yes }\end{array}$ & 15 \\
\hline No & 5 \\
\hline Not reported & 8 \\
\hline Where do you usually sleep? & \\
\hline Hostel & 20 \\
\hline Supported accommodation & 2 \\
\hline Squat & 2 \\
\hline Friend's house & 1 \\
\hline Street & 1 \\
\hline Bus & 1 \\
\hline Not reported & 1 \\
\hline
\end{tabular}

*The accident and emergency department of a hospital.
Table 3 Challenges to discussing palliative care with people experiencing homelessness

\begin{tabular}{ll}
\hline Themes & Subthemes \\
\hline Attitude to death & Death and dying are taboo \\
Recovery focus & Fear of discussing death \\
& Young age of people experiencing \\
& homelessness with advanced ill health \\
& Most deaths seen as avoidable, \\
pressure to never give up on someone
\end{tabular}

other than supporting engagement with substance misuse services for people with addiction issues.

It's really hard to have that conversation...we're trained to do recovery.... our hostel is commissioned to engage people with support and recovery... getting better, moving into jobs, whatever... and then... it's really hard to come out of that mind set and go into another... which is... death. (Hostel staff)

It was also very difficult for staff to talk about palliative care preferences with people who were young and who had, for example, advanced liver disease, knowing that if they were to stop drinking the disease progression may stop and they could potentially live for many more years. This contributed to their belief that they should 'never give up' on someone. Furthermore, many staff felt as if they had failed someone if they 'couldn't save them'.

There was a bit of fear coming from my part... feeling that I've let down the client, and you can see the desperation in the client, so it's a bit of both of us... Honestly, I just never let up [trying to engage homeless person with services]... I don't want anyone dying on me. (Person with lived experience of homelessness who is now a mentor for people currently experiencing homelessness)

These factors accentuated dissonance in identifying young people with potentially treatable conditions as patients requiring palliative care. This posed a block to conversations around the potential benefits of palliative care for this group. 
They sort of...they could be classed as palliative but they are also reversibly palliative. So if you don't stop drinking, if you don't stop doing these things, then you are probably going to die in 6 months. And it's a little bit difficult sometimes to class them as palliative, when you have a reversible cause to it. (Healthcare professional)

\section{Theme 3: fear of impact on homeless person and staff}

Huge emotional burdens were described by staff who felt they had to 'fix' people despite it becoming increasingly clear that a person was approaching the end of their life:

It's not easy to support a client who you know is terminal. Errm, so on one hand you want to be there to support them, on the other, you have to manage your own feelings around having to do that. (Hostel staff)

There was recognition of the vulnerability and fragility of many people experiencing homelessness by all participant groups. Hostel residents described how substances or alcohol may be used to 'numb' or block painful memories or experiences. This fragility and avoidance also posed a challenge to discussions about palliative care as people experiencing homelessness did not want to contemplate worsening health and possible death.

Researcher: Do you think that people here [in the hostel] are...concerned about...the fears of dying?

Hostel resident: A lot of them [people experiencing homelessness] probably have seen a lot of trauma in their lives. And they want to get away from it so they drink a lot. But then, they don't go and see GPs because they don't want to hear the realities.

Staff feared that raising issues related to palliative care and deteriorating health may be detrimental to service users' well-being, their relationships with them and the potential for future engagement with services.

I don't know how I would broach it [palliative care], but also its knowing how to ....recover the conversation if it goes really wrong. You know? If it results in the person....reacting really badly and then they have lost all their trust in me and this massive relationship that I have built up over several years is completely lost. You know? (Outreach worker)

Participants were also concerned that palliative care discussions may cause service users to feel abandoned, which may paradoxically lead to an increase in harmful behaviours, rather than an opportunity to consider how to improve quality of life.

Sometimes they're very mentally impaired, they don't know whether they're coming or going sometimes... to have that conversation... Is it going to go make them go drink even more, now they know they're not even going to last that long? (Person with experience of homelessness who is now working as a mentor for others experiencing homelessness.)

\section{Theme 4: uncertainty}

The uncertain trajectories of people with illnesses such as advanced liver disease was particularly challenging. People with advanced liver disease could appear gravely ill but, following emergency hospital treatment, improve considerably. Examples were given of individuals being issued warnings such as 'if you don't stop drinking, you will be dead in 6 months' which were rarely followed by discussions about choices. Participants described witnessing people issued with such warnings living far longer than expected. This did little to motivate change or desire to plan.

It's like "oh well, I've survived that" or it's "I was told when I was 25, I would only last so many years, and I've done this much, so it can't be that bad, I've heard all this before"... so when doctors say "you've only got so long”... I don't think that's very helpful (Hostel staff)

The uncertainty about services that could provide support for people who are homeless with advanced ill health posed a major block to conversations about palliative care as many professionals felt they had no alternatives to offer.

Yeah it's on the cards [death], but exactly how it's going to happen we don't know. And where is going to take him? I don't know. So it feels like the best we can do is almost... plan for what we can do here. So that doesn't leave a lot of choices, it only makes us able to erm, to deal with that situation as best we can when it comes. (Hostel staff)

The lack of certainty about appropriate places of care for people was also voiced by hostel residents:

A: living here [in the hostel] ... if you are really sick.... you could pass away in the middle of the night... So they take them out in a body bag....and I've seen that. So I think you would be better off... if they are in a care home. The sort that has people there 24 hours...

B: but there aint no care homes around! Where are you going to put all of these people? (People experiencing homelessness)

It was also not clear to hostel staff whether hostel residents would be able to access traditional providers of palliative care, such as care homes due to the young age at which they may require them. Often care homes were inaccessible as they accept patients who are 65 years or older.

Our client who is a former alcoholic who also has dementia... he may not get on well with an 80 year old in a care home. So that is a big gap for our clients and erm it can be a tough one to navigate. (Hostel staff) 
Much uncertainty was therefore expressed about when to have conversations about palliative care. Given this uncertainty, many participants felt identifying someone as being at the end of life was necessary before discussions could take place.

If the doctor says clinically you only have six months, then we can pass that on, because that's got a doctor's professionalism behind it. So then I could feel confident in saying, 'Look, this is what the doctor said, you've got sixmonths' (Person with previous experience of homelessness who now works as a mentor for others experiencing homelessness)

As certainty in this regard was rare, and information sharing often incomplete or inadequate, this posed a major block to palliative care conversations.

For people with illnesses such as cancer, with more predictable trajectories professionals reported more success in accessing services.

I do wonder...I'm not sure all the professionals would be around the table if it wasn't for the fact that it was a cancer diagnosis. Because that's quite straightforward. It's quite...the trajectory is known... (Hostel staff)

Further uncertainty surrounded which professional groups would be best placed to have discussions with people experiencing homelessness about palliative care. Some hostel staff felt healthcare professionals would be in a better position, given their medical experience and knowledge.

I mean it should be kind of medically led really, because you are putting a lot of responsibility on yourself without maybe being qualified. (Hostel staff)

Hostel staff also described lacking confidence, related partly to recovery-focused approaches, their lack of medical qualifications and apprehension about managing the consequences of such conversations.

Maybe nurses should perhaps have more of those [palliative] conversations. Because they are more equipped to deal with the response. I think we need to be really careful to not put our staff in situations where they are...yeah... they are not counsellors and we are always like 'don't start unpicking something when you can't deal with what comes back at you' and it's kind of the same thing really, isn't it? (Hostel manager)

However, healthcare professionals cited their lack of developed relationships with people experiencing homelessness and limited experience of the challenges of homelessness as challenges in broaching these issues.

Hostel staff are the ones that see the everyday life of that patient. They have that relationship, the client is more likely to trust them with their true wishes or various bits of information. (Healthcare professional)
While many hostel staff did not feel comfortable or confident discussing palliative care, some described discussion strategies that recognised the uncertainty and complexity of supporting service users with advanced ill health. These strategies involved respecting decisions made by individuals, while always providing support and the opportunity to change their mind.

They're scared, too ill to change, so we work with what we've got. I've got a gentleman who's... had three or four attempts at detox. His head is saying 'if I don't do this, I am going to die'... He knows that, we've had conversations about that. But... he's got to make that decision; it's about the choices we give our clients. And we get anxious because we can't change that person. And I think sometimes we have to give that back to them...but keep on supporting them in whatever decisions they make (Hostel manager)

Figure 2 outlines how one hostel worker incorporates uncertainty into discussions about deteriorating health and palliative care. Discussions focus on the individual's insights and wishes, including an exploration of how this might change should their health deteriorate. The emphasis is on empowering people to think and talk about future care options they feel are acceptable, and those which are not.

\section{DISCUSSION}

This research highlights how conversations with homeless people about deteriorating health, the future and care preferences are currently largely avoided due to discomfort and for fear of damaging relationships or making situations worse. If talking about preferences with homeless people with ill health was reconceptualised as a conversation about how a person could be supported to live well, rather than die well, it may be an easier topic to broach. There is a need to incorporate parallel planning into the care and support of people experiencing homelessness whose health is a concern, given the uncertainty described in this research.

\section{Links to previous research}

In this research, we noted avoidance, denial and reluctance among people experiencing homelessness to talk about death, dying and the choices available to them as their health deteriorates. Healthcare professionals described their lack of developed relationships with service users as a barrier to palliative care discussions. In previous research, nursing students described anxiety around discussing death and dying with this group, yet completion of the advance directive with this group was rated as less challenging than anticipated. ${ }^{47}$ People experiencing homelessness have been willing to talk about end-of-life care wishes ${ }^{24}$ and complete advance directives $^{48}$ in previous research, particularly when one to one support is provided. ${ }^{1935-37}$ In this research, avoidance and denial of these issues was apparent. 


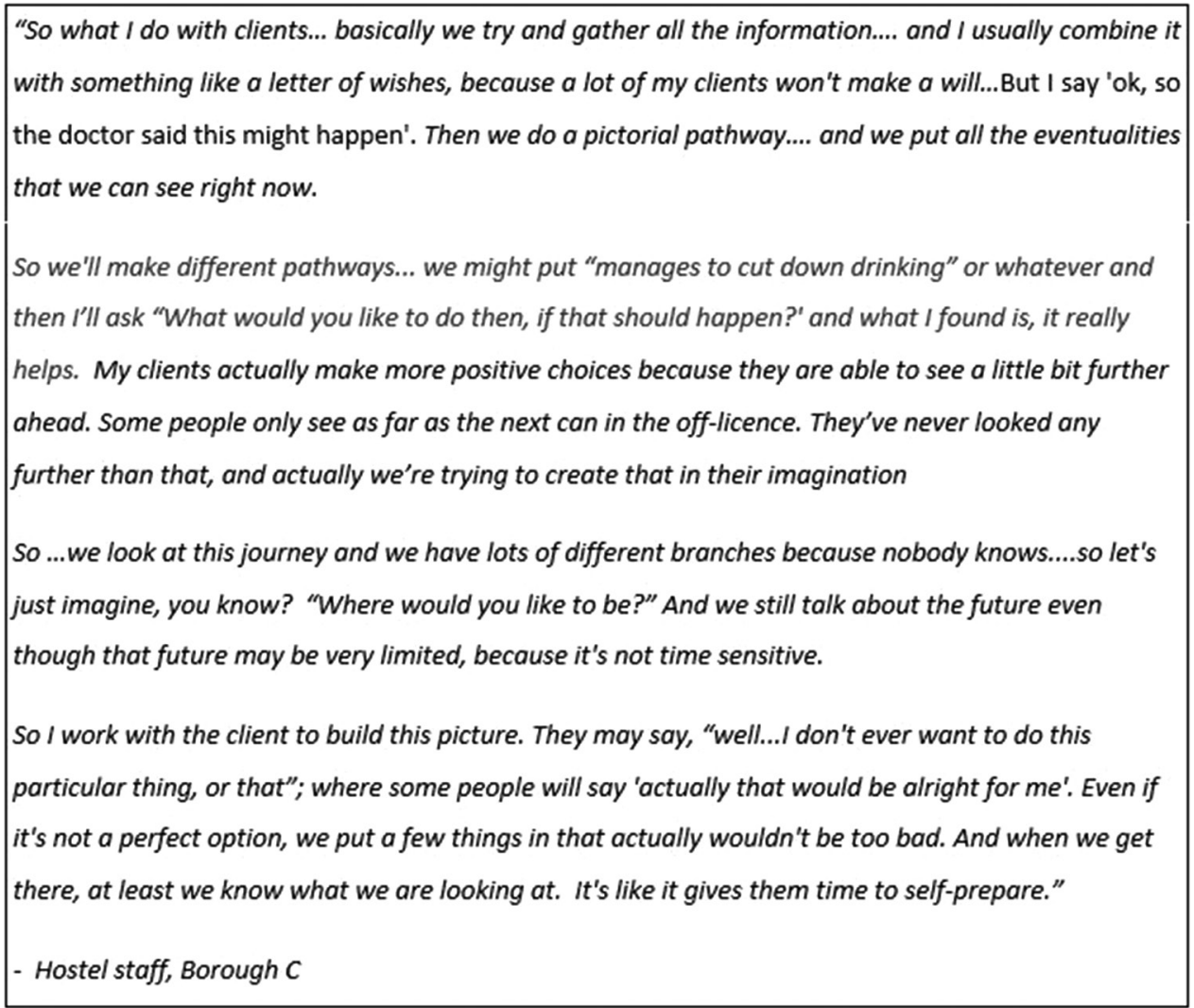

Figure 2 Incorporating uncertainty into discussions about the future with homeless people with advanced ill health.

Spirituality has been identified as an important factor when considering end-of-life wishes with people experiencing homelessness in previous research ${ }^{19} 2427$ yet was not reflected in our findings. These contrasts highlight the need for psychologically informed, person-centred approaches to supporting people experiencing homelessness and respect for individual preferences. ${ }^{49}{ }^{50}$ Many homelessness services in the UK are adopting a "psychologically informed environment' (PIE) model.$^{51}$ The aim of PIEs is to 'enable people experiencing homelessness to make changes in their lives, ${ }^{52}$ For people who are homeless and also potentially have palliative care needs, this could extend to consideration of how to improve quality of life, however long that lasts.

Uncertainty, particularly for people with liver disease, presented a range of challenges for palliative care discussions with people experiencing homelessness in this research. Uncertainty for non-homeless patients with liver disease has been described as a barrier to palliative care,${ }^{53-56}$ yet the early introduction of palliative care for patients with liver disease (awaiting transplantation) has proved beneficial in improving mood and reducing symptom burden. ${ }^{57}$ The majority of previous research exploring parallel planning and early introduction of palliative care has been with non-homeless patients with cancer, ${ }^{58}$ for whom the trajectories of illnesses are clearer.

Uncertainty around when a person experiencing homelessness could be considered palliative, appropriate places of care for people and also the role of hostel staff in supporting service users with advanced ill health have also been described previously in the literature. ${ }^{11} 1828-303260$

Mishel's reconceptualised uncertainty in illness theory $^{61}{ }^{62}$ views uncertainty as an opportunity for change and growth. In line with this theory, and based on the findings of this research, we proposes that uncertainty around a person's illness could be viewed as an opportunity to engage people in conversations and planning about a range of potential outcomes (using parallel planning). By having conversations about current health and preferences for palliative care with people experiencing homelessness about whom staff are concerned, rather waiting until some has been idenitfied as 'palliative', uncertainty may be reappraised as an opportunity for planning, rather than a barrier to conversations or action. We suggest that early discussions about a person's health, their behaviour and their aspirations may empower them to re-appraise the uncertainty surrounding their health. For example, moving the emphasis of conversations from warnings (you are going to die if you do not stop drinking) to discussions (what do you want or feel able to do at present about your drinking?) may make conversations about quality of life, and eventually palliative care more palatable.

Hostel staff described huge uncertainty and a lack of options for services users with advanced ill health. 


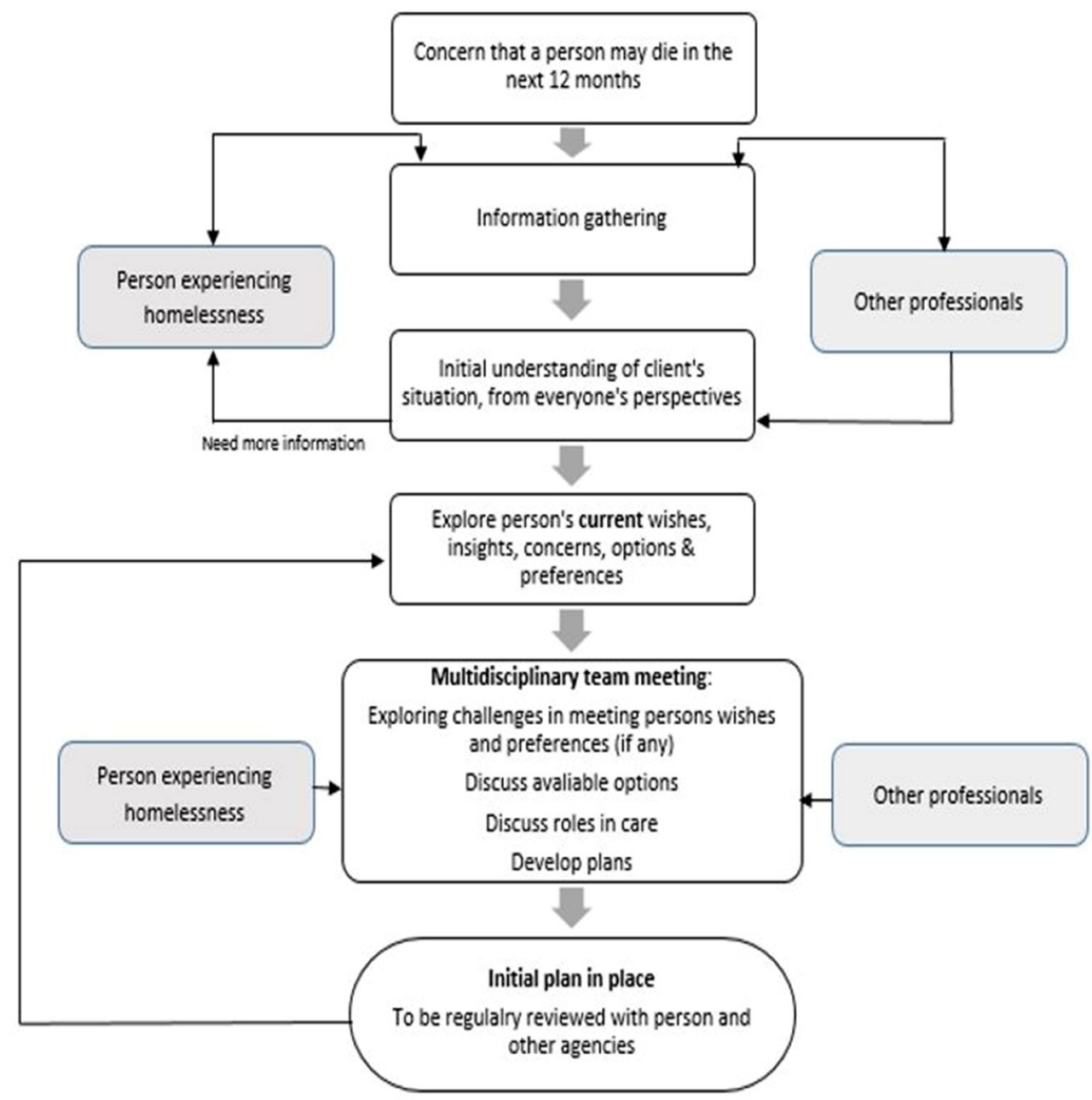

Figure 3 A multidisciplinary response to exploring the concerns and wishes of people experiencing homelessness and those that support them to facilitate a person-centred approach to care.

In response, we propose facilitating greater multidisciplinary working to both support hostel staff and raise the understanding and awareness of other professional groups regarding the needs and preferences of people who are homeless. In our research, the fear of talking about death and about causing more harm than good through bringing up sensitive issues was a major block to conversations. We propose that conversations about how individuals see their health and what they think might help them feel better may be a more accessible way to begin to identify and address some health issues. A suggested strategy for incorporating a parallel planning based approach for people experiencing homelessness is outlined in figure 3.

\section{Parallel planning}

Stage 1. Identifying people who staff fear could be approaching the end of life

In this research, we have seen that the health of many people experiencing homelessness is poor; therefore, this model may be appropriate for many people with complex needs. In order to focus more specifically on people who may require palliative care, we suggest that consideration of whether staff feel a client's health is of significant concern could act as a trigger for thinking about future care preferences and planning, rather than waiting until a person has been identified as palliative before conversations about insights and preferences begin. This does not mean active treatments and recovery-focused options cannot be pursued simultaneously, but may help in the development of multiple plans, that can be adopted as and when needs or preferences change.

Stage 2. Gathering information, exploring wishes, insights, options and concerns

Conversations exploring the individual's conceptualisation of their health and their options, and what they feel could improve their quality of life may be easier to initiate than conversations about deteriorating health, death or dying. Figure 3 does not specify who should initiate such conversation as the most appropriate person (or persons) is likely to vary for each individual.

In the research, we heard how node-link mapping $(\mathrm{NLM})^{63}$ was used by some hostel staff to explore aspirations and future palliative care preferences. NLM is based on the same cognitive behavioural principles as motivational interviewing ${ }^{63}$ and enables people experiencing homelessness to dictate the content and pace 
of conversations exploring their health, their perceived options and their future wishes. NLM involves structuring and visually representing issues on a series of maps which may relate to a single topic (eg, substance or alcohol use) or may represent concepts such as health or well-being. This facilitates the identification and exploration of shared meanings, goals and care preferences, which can be pictorially represented and recorded. ${ }^{64}$ Over time, if both parties feel comfortable to explore these areas, such conversations may extend into discussions about potential future palliative care preferences.

\section{Stage 3. Multidisciplinary support and reviewing plans}

In light of the uncertainty and pressure perceived by hostel staff, greater multidisciplinary working could support staff and service users by bringing together learning and expertise from different professional groups to respond to the needs and preferences of service users. The responsibility of supporting the wishes of the individual is shared, potentially reducing burdens experienced by hostel staff.

Potential challenges to supporting the individual's wishes could be discussed to create mutual understanding and provide the opportunity to develop multiple, realistic, parallel plans to facilitate person-centred planning and care. An important aspect of this approach is returning to the individual to assess their current wishes and concerns. Plans may need to be reviewed and adapted (both best case and worst case plans) to ensure that they are responsive to potentially changing needs or preferences.

\section{Strengths and limitations}

This is the largest UK study exploring views and experiences of people experiencing homelessness and those supporting them regarding palliative care conversations.

While all participants were service users or providers in London, the challenges described and the strategy suggested for managing uncertainty could be beneficial in other locations. The voices of people experiencing homelessness are represented throughout this research; however, those with severe substance misuse issues and those sleeping rough (and not accessing day centres) are likely to be under-represented. Our results were discussed within a steering group composed of people with lived experience of homelessness, palliative care researchers and clinicians and professionals in inclusion healthcare who concurred that the findings resonated with their experiences.

\section{Unanswered questions and future research}

Methods for providing palliative care support for people who are homeless need urgent consideration. The lack of facilities that can provide adequate support to people who are homeless with high support needs demonstrates the need to strengthen and foster collaborations between partners from health, housing, social, homelessness and palliative care services. Also, given the uncertainties in supporting people who are homeless and experiencing advanced ill health, we propose parallel planning as a method for identifying, exploring and respecting the wishes of individuals as their health deteriorates. For some people, moving the focus of conversations away from 'recovery' towards 'living well/quality of life' has the potential to facilitate more patient-centred, multidisciplinary care and contingency planning. Future research is needed to explore the viability of this approach and evaluate its effectiveness. It is essential that all professional groups are provided with training and support (potentially from palliative care services) to bring about this shift in thinking, and that robust evaluation of this training is completed.

\section{CONCLUSION}

This research highlights the need for a different approach to supporting people who are homeless and are experiencing advanced ill health, one that incorporates uncertainty and promotes choice. We propose parallel planning and mapping as a method for working with uncertainty and complexity. We acknowledge that this approach will not always be straightforward, nor will it be suitable for everyone, yet moving the focus of conversations about the future away from death and dying, towards the present and the future may a helpful place to start.

Acknowledgements The authors would like to thank the managers, employees and users of homelessness services across the three London Boroughs.

Contributors CS, PS, SD and JL conceptualised the study. CS, BH, JD, BV and PK collected the data. $\mathrm{BH}$ and $\mathrm{CS}$ analysed the data. $\mathrm{BH}$ drafted the initial manuscript. $\mathrm{CS}, \mathrm{PS}, \mathrm{JL}, \mathrm{NH}, \mathrm{DH}, \mathrm{JD}, \mathrm{BV}, \mathrm{PK}, \mathrm{SD}$ and NB reviewed the manuscript, approved the final manuscript and agree to be accountable for all aspects of the work.

Funding Initial seed funding and support for this research was provided by Coordinate My Care to facilitate CS in the development of this research, following which a grant was obtained from The Oak Foundation (OCAY-14-574) to support BH's post. Professor Paddy Stone - Marie Curie Chair in Palliative and End of life care is supported by Marie Curie Chair's grant - 509537 BV - Senior Research Associate is supported by Marie Curie Chair's grant - $509537 \mathrm{JL}-$ Senior Research Fellow is supported by Marie Curie Programme and Core grants (50\% Programme; $50 \%$ Core) - 531645 (Programme) and 531477 (Core) SD- Research Nurse is supported by Marie Curie Programme grant -531645 . NH and JD are Pathway Employees. NB is employed by St Mungos.

Competing interests None declared.

Ethics approval Ethical approval was obtained from the Research Ethics Committee of University College London (reference-6927/001).

Provenance and peer review Not commissioned; externally peer reviewed. Data sharing statement № additional data are available for this article.

Open Access This is an Open Access article distributed in accordance with the Creative Commons Attribution Non Commercial (CC BY-NC 4.0) license, which permits others to distribute, remix, adapt, build upon this work non-commercially, and license their derivative works on different terms, provided the original work is properly cited and the use is non-commercial. See: http://creativecommons.org/ licenses/by-nc/4.0/

(C) Article author(s) (or their employer(s) unless otherwise stated in the text of the article) 2017. All rights reserved. No commercial use is permitted unless otherwise expressly granted.

\section{REFERENCES}

1. Public Health England. Guidance to Homelessness: applying all our health: Evidence and guidance to enable healthcare professionals make improvements against wider factors that affect health and 
wellbeing. 2016 https://www.gov.uk/government/publications/ homelessness-applying-all-our-health

2. Department for communities and local government. Rough sleeping statistics Autumn 2016, England. 2017 https://www.gov.uk/ government/statistics/rough-sleeping-in-england-autumn-2016

3. Medcalf $P$, Russell GK. Homeless healthcare: raising the standards. Clin Med 2014;14:349-53.

4. Hwang SW, Wilkins R, Tjepkema M, et al. Mortality among residents of shelters, rooming houses, and hotels in Canada: 11 year follow-up study. BMJ 2009;339:b4036.

5. Hewett N, Halligan A, Boyce T. A general practitioner and nurse led approach to improving hospital care for homeless people. BMJ 2012;345:e5999.

6. Baggett TP, Chang Y, Porneala BC, et al. Disparities in Cancer Incidence, Stage, and Mortality at Boston Health Care for the Homeless Program. Am J Prev Med 2015;49:694-702.

7. Fazel S, Geddes JR, Kushel M The health of homeless people in high-income countries: descriptive epidemiology, health consequences, and clinical and policy recommendations. The Lancet 2014;384:1478.

8. Thomas B. Homelessness Kills: an analysis of the mortality of homeless people in early twenty-first century England. London: Crisis and The University of Sheffield, 2012. 978-1-899257-78-2.

9. McCormick B, White J. Hospital care and costs for homeless people. Clin Med 2016;16:506-10.

10. Collier R. Bringing palliative care to the homeless. CMAJ 2011;183:E317-E318.

11. Håkanson C, Sandberg J, Ekstedt M, et al. Providing palliative care in a Swedish support home for people who are homeless. Qual Health Res 2016;26:1252-62.

12. Rae $\mathrm{BE}$, Rees $\mathrm{S}$. The perceptions of homeless people regarding their healthcare needs and experiences of receiving health care. $J \mathrm{Adv}$ Nurs 2015;71:2096-107.

13. Homeless Link. The unhealthy state of homelessness: health audit results 2014: Homeless link, 2014

14. Hudson BF, Flemming K, Shulman C, et al. Challenges to access and provision of palliative care for people who are homeless: a systematic review of qualitative research. BMC Palliat Care 2016;15:96.

15. Hudson BF, Shulman C, Stone P. 'Nowhere else will take him' Palliative care and homelessness. J Palliat Med 2017;24.

16. Shulman C, Hudson BF, Low J, et al. End-of-life care for homeless people: a qualitative analysis exploring the challenges to access and provision of palliative care. Palliat Med 2017;0:026921631771710.

17. McNeil R, Guirguis-Younger M. Dignity in design: the siting and design of community and shelter-based health facilities for homeless person. In: Guirguis-Younger M, McNeil R, Hwang SW. Homelessness and Health in Canada. Canada: University of Ottawa Press, 2014:233-51.

18. McNeil R, Guirguis-Younger M, Dilley LB. Recommendations for improving the end-of-life care system for homeless populations: A qualitative study of the views of Canadian health and social services professionals. BMC Palliat Care 2012;11:14.

19. Song J, Bartels DM, Ratner ER, et al. Dying on the streets: homeless persons' concerns and desires about end of life care. J Gen Intern Med 2007;22:435-41.

20. Song J, Ratner ER, Bartels DM. Dying while homeless: is it a concern when life itself is such a struggle? J Clin Ethics 2005;16:251-61.

21. Henry B, Dosani N, Huynh L, et al. Palliative care as a public health issue: understanding disparities in access to palliative care for the homeless population living in Toronto, based on a policy analysis. Curr Oncol 2017;:24:187-91.

22. Mitchell G, Price J. Developing palliative care services in regional areas. The Ipswich Palliative Care Network model. Aust Fam Physician 2001;30:59-62.

23. Wee B. Ambitions for palliative and end-of-life care. Clin Med 2016;16:213-4.

24. Tarzian AJ, Neal MT, O'Neil JA. Attitudes, experiences, and beliefs affecting end-of-life decision-making among homeless individuals. $J$ Palliat Med 2005;8:36-48.

25. Song J, Ratner ER, Bartels DM, et al. Experiences with and attitudes toward death and dying among homeless persons. J Gen Intern Med 2007:22:427-34.

26. Ko E, Nelson-Becker $\mathrm{H}$. Does end-of-life decision making matter? Perspectives of older homeless adults. Am J Hosp Palliat Care 2014;31:183-8

27. Ko E, Kwak J, Nelson-Becker H. What constitutes a good and bad death?: perspectives of homeless older adults. Death Stud 2015;39:422-32.

28. McNeil R, Guirguis-Younger M, Dilley LB, et al. Harm reduction services as a point-of-entry to and source of end-of-life care and support for homeless and marginally housed persons who use alcohol and/or illicit drugs: a qualitative analysis. BMC Public Health 2012;12:312.

29. McNeil R, Guirguis-Younger M. Illicit drug use as a challenge to the delivery of end-of-life care services to homeless persons: perceptions of health and social services professionals. Palliat Med 2012;26:350-9.

30. Krakowsky Y, Gofine M, Brown P, et al. Increasing access-a qualitative study of homelessness and palliative care in a major urban center. Am J Hosp Palliat Care 2013;30:268-70.

31. MacWilliams J, Bramwell M, Brown S, et al. Reaching out to Ray: delivering palliative care services to a homeless person in Melbourne, Australia. Int J Palliat Nurs 2014;20:83-8.

32. Webb WA. When dying at home is not an option: exploration of hostel staff views on palliative care for homeless people. Int J Palliat Nurs 2015;21:236-44.

33. Podymow T, Turnbull J, Coyle D. Shelter-based palliative care for the homeless terminally ill. Palliat Med 2006;20:81-6.

34. McNeil R, Guirguis-Younger M. Harm reduction and palliative care: is there a role for supervised drug consumption services? J Palliat Care 2012;28:175-7. ISSN 08258597.

35. Song J, Wall MM, Ratner ER, et al. Engaging homeless persons in end of life preparations. J Gen Intern Med 2008;23:2031-45.

36. Leung AK, Nayyar D, Sachdeva M, et al. Chronically homeless persons' participation in an advance directive intervention: A cohort study. Palliat Med 2015;29:746-55.

37. Song J, Ratner ER, Wall MM, et al. Effect of an end-of-life planning intervention on the completion of advance directives in homeless persons: a randomized trial. Ann Intern Med 2010;153:76.

38. Sumalinog R, Harrington K, Dosani N, et al. Advance care planning, palliative care, and end-of-life care interventions for homeless people: A systematic review. Palliat Med 2017;31:109-19.

39. Mayor of London. CHAIN annual report: greater London april 2015march 2016. London: Greater London Authority, 2016. https://files. datapress.com/london/dataset/chain-reports/2017-06-30T09:03:07. 84/Greater London full 2016-17.pdf

40. Bhatti V, Currie D, Sapsaman T. Atlas of services for homeless people in London: London Housing Foundation, 2016.

41. Bax A, Hewett N. Pathway annual report. 2015 https://www.pathway. org.uk/wp-content/uploads/2013/02/Pathway-Annual-Report-2015. pdf

42. Finlayson S, Boelman V, Young R. Saving lives, saving money: how homeless health peer advocacy reduces health inequalities. London: The Young Foundation, Groundswell, The Oak Foundation, 2016.

43. St Mungo's Ending Homeless and Rebuilding Lives. St Mungo's apprenticeship scheme. 2015 http://www.mungos.org/ apprenticeship scheme: St Mungos Broadway

44. Kerr C, Nixon A, Wild D. Assessing and demonstrating data saturation in qualitative inquiry supporting patient-reported outcomes research. Expert Rev Pharmacoecon Outcomes Res 2010;10:269-81.

45. Braun V, Clarke V. Using thematic analysis in psychology. Qual Res Psychol 2006;3:77-101.

46. Willig C. Beyond appearances: A critical realist approach to social constructionist work. In: Nightingsale I, Cromby J. Social constructionist psychology: a critical analysis of theory and practice. Buckingham, 1999.

47. Nash W, Mixer SJ, McArthur PM, et al. The moral courage of nursing students who complete advance directives with homeless persons. Nurs Ethics 2016;23:743-53.

48. Norris WM, Nielsen EL, Engelberg RA, et al. Treatment preferences for resuscitation and critical care among homeless persons. Chest 2005;127:2180-7.

49. Breedvelt J. Psychologically informed environments: a literature review. London: Mental Health Foundation St Mungos, 2016. https:// www.mentalhealth.org.uk/sites/default/files/pies-literature-review.pdf

50. Johnson R, Haigh R. Complex trauma and its effects: perspectives on creating an environment for recovery. Brighton: Pavilion Publishing, 2012.

51. Haigh R, Harrison $\mathrm{T}$, Johnson $\mathrm{R}$, et al. Psychologically informed environments and the "Enabling Environments" initiative. Housing, Care and Support 2012;15:34-42.

52. Keats $\mathrm{H}$, Maguire $\mathrm{N}$, Johnson R, et al. Psychologically informed services for homeless people good practice guide: Department of Communities and Local Government. 2012 http://www. rjaconsultancy.org.uk/6454\%20clg\%20pie\%20operational\% 20document\%20aw-1.pdf

53. Kimbell B, Boyd K, Kendall M, et al. Managing uncertainty in advanced liver disease: a qualitative, multiperspective, serial interview study. BMJ Open 2015;5:e009241. 
54. Potosek J, Curry M, Buss M, et al. Integration of palliative care in end-stage liver disease and liver transplantation. J Palliat Med 2014;17:1271-7.

55. Poonja Z, Brisebois A, van Zanten SV, et al. Patients with cirrhosis and denied liver transplants rarely receive adequate palliative care or appropriate management. Clin Gastroenterol Hepatol 2014;12:692-8.

56. Larson AM. Palliative care for patients with end-stage liver disease. Curr Gastroenterol Rep 2015;17:440.

57. Baumann AJ, Wheeler DS, James M, et al. Benefit of early palliative care intervention in end-stage liver disease patients awaiting liver transplantation. J Pain Symptom Manage 2015;50:882-6.

58. Dionne-Odom JN, Azuero A, Lyons KD, et al. Benefits of early versus delayed palliative care to informal family caregivers of patients with advanced cancer: outcomes from the ENABLE III randomized controlled trial. J Clin Oncol 2015;33:1446-52.

59. Temel JS, Greer JA, Muzikansky A, et al. Early palliative care for patients with metastatic non-small-cell lung cancer. N Engl J Med 2010;363:733-42.
60. Kushel MB, Miaskowski C. End-of-life care for homeless patients: 'she says she is there to help me in any situation'. JAMA 2006;296:2959-66.

61. Mishel MH. Reconceptualization of the uncertainty in illness theory. Image J Nurs Sch 1990;22:256-62.

62. Mishel MH. Uncertainty in illness. Image J Nurs Sch 1988;20:225-32.

63. Dansereau DF, Joe GW, Simpson DD. Node-link mapping: a visual representation strategy for enhancing drug abuse counseling. $J$ Couns Psychol 1993;40:385-95.

64. NHS. Routes to recovery ITEP \& BTEl: new approaches to psychosocial intervention. London: National Treatment Agency for Substance Misuse, The University of Birmingham, 2008 http://www.nta.nhs.uk/uploads/itep_routes_to_recovery_summary 180209.pdf

65. Homeless Link. Support for single homeless people in England annual review 2016. London: Homeless Link, 2016. http://www. homeless.org.uk/sites/default/files/site-attachments/Full\%20report\% 20-\%20Support\%20for\%20single\%20people\%202016.pdf 